03, 12

\title{
Оптические свойства нанопорошков сульфида цинка и гетеронаноструктур $\mathrm{ZnS} / \mathrm{Ag}_{2} \mathrm{~S}$
}

\author{
(С) С.И. Садовников, И.Д. Попов \\ Институт химии твердого тела УрО РАН, \\ Екатеринбург, Россия \\ E-mail: sadovnikov@ihim.uran.ru
}

Поступила в Редакцию 12 мая 2020 г.

В окончательной редакциии 3 июня 2020 г.

Принята к публикации 9 июня 2020 г.

\begin{abstract}
Методом химического осаждения из водных растворов синтезированы нанопорошки сульфида цинка $\mathrm{ZnS}$ и гетеронаноструктуры $\mathrm{ZnS} / \mathrm{Ag}_{2} \mathrm{~S}$. Изменение соотношения между концентрациями реагентов позволило получить нанопорошки $\mathrm{ZnS}$ со средним размером частиц от 2 до $10 \mathrm{~nm}$. Размер наночастиц $\mathrm{Ag}_{2} \mathrm{~S}$ в полученных гетеронаноструктурах составляет $9-30 \mathrm{~nm}$, толщина поверхностного слоя $\mathrm{ZnS}$ равна $4-5 \mathrm{~nm}$. Измерены спектры диффузного отражения наноструктурированного $\mathrm{ZnS}$ и гетеронаноструктур $\mathrm{ZnS} / \mathrm{Ag}_{2} \mathrm{~S}$. На основе анализа полученных спектров оценена ширина запрещенной зоны $E_{g}$ в изученных сульфидных наноструктурах. При уменьшении размера наночастиц от 10 до $2 \mathrm{~nm}$ величина $E_{g}$ в нанопорошках $\mathrm{ZnS}$ увеличивается в диапазоне $3.17-3.36 \mathrm{eV}$. Рост содержания $\mathrm{Ag}_{2} \mathrm{~S}$ в гетеронаноструктурах $\mathrm{ZnS}_{2} \mathrm{Ag}_{2} \mathrm{~S}$ приводит к уменьшению ширины запрещенной зоны и снижению интенсивности люминесценции.
\end{abstract}

Ключевые слова: сульфид цинка, сульфид серебра, гетеронаноструктура, оптическое поглощение, запрещенная зона.

DOI: 10.21883/FTT.2020.11.50106.107

\section{1. Введение}

Сульфиды цинка $\mathrm{ZnS}$ и серебра $\mathrm{Ag}_{2} \mathrm{~S}$ - широко востребованные полупроводниковые соединения [1-9]. Они используются в инфракрасных датчиках и детекторах, лазерах, люминофорах, солнечных элементах, светодиодах, фотохимических ячейках, катализаторах, переключателях сопротивления и энергонезависимых устройствах памяти [10-17].

Ширина запрещенной зоны $E_{g}$ кубического (пр.гр. $F \overline{4} 3 m) \alpha-\mathrm{ZnS}$, имеющего структуру сфалерита (тип B3), составляет 3.50-3.76 eV [9]. Диаметр экситона в крупнокристаллическом (bulk) сульфиде цинка равен $4.8-5.2 \mathrm{~nm}$ [9]. Низкотемпературная полупроводниковая фаза сульфида серебра существует при температуре ниже $450 \mathrm{~K}$ и имеет моноклинную (пр.гр. $P 2_{1} / c$ ) структуру типа акантита $\alpha-\mathrm{Ag}_{2} \mathrm{~S}$. Ширина запрещенной зоны сульфида серебра со структурой акантита $\alpha-\mathrm{Ag}_{2} \mathrm{~S}$ равна 0.9-1.1 eV, диаметр экситона равен $2.8 \mathrm{~nm}$ [5-8].

Увеличение ширины запрещенной зоны наноструктурированных сульфидов и гетеронаноструктур наблюдается при уменьшении размеров наночастиц и при создании сульфидных нанокомпозитов двух разных металлов $[1,2,9]$. Уменьшение размера наночастиц меньше размера экситона позволяет регулировать ширину запрещенной зоны. Диаметр экситона для $\mathrm{ZnS}$ и $\mathrm{Ag}_{2} \mathrm{~S}$ мал $(\sim 5.0$ и $\sim 2.8 \mathrm{~nm}$ соответственно) и получать стабильные наночастицы такого размера сложно. Более простым способом является получение полупроводниковых нанокомпозитов, состоящих из наночастиц сульфидов цинка и серебра. В идеальном случае ширина запрещенной зоны гетеронаноструктур на основе $\mathrm{ZnS}$ и $\mathrm{Ag}_{2} \mathrm{~S}$ может меняться от 1.0 до $4.0 \mathrm{eV}$, что соответствует изменению положение края оптического поглощения от инфракрасного до ближнего ультрафиолетового диапазона. Разработка таких гетеронаноструктур позволит расширить спектральную чувствительность сульфидных полупроводников в видимой области спектра, получить новые наноматериалы для твердотельных УФ-лазеров, быстродействующих переключателей сопротивления [1-3].

Однако до сих пор проблема синтеза гетеронаноструктур на основе наноструктурированных сульфидов цинка и серебра еще не решена полностью. Систематические исследования таких гетеронаноструктур также отсутствуют. Известно несколько отдельных работ по синтезу кристаллов $\mathrm{ZnS}$, допированных серебром [18], по синтезу нанокомпозитов $\mathrm{ZnS} / \mathrm{Ag}_{2} \mathrm{~S}$ методом катионного обмена $[19,20]$, по синтезу наночастиц $\mathrm{Ag}_{2} \mathrm{~S} @ \mathrm{ZnS}$ типа ядро-оболочка в водных растворах с использованием микроволнового излучения [21], по гидрохимическому осаждению гетеронаноструктур на основе $\mathrm{ZnS}$ и $\mathrm{Ag}_{2} \mathrm{~S}$ [22]. Синтез и оптические свойства пустотелых наночастиц $\mathrm{ZnS}-\mathrm{Ag}_{2} \mathrm{~S}$ типа ядро-оболочка и нанокомпозитов $\mathrm{ZnS} / \mathrm{Ag}_{2} \mathrm{~S}$ и $\mathrm{Ag}_{2} \mathrm{~S} / \mathrm{ZnS}$ типа ядро-оболочка описаны в работах $[23,24]$.

В настоящей работе изучено влияние условий химического осаждения порошков наноструктурированного сульфида цинка и гетеронаноструктур $\mathrm{ZnS} / \mathrm{Ag}_{2} \mathrm{~S}$ на размер и фазовый состав сульфидных наночастиц, на их оптические свойства (спектры диффузного отражения, ширину запрещенной зоны и люминесценцию). Особый интерес представляют свойства гетеронаноструктур 
$\mathrm{ZnS} / \mathrm{Ag}_{2} \mathrm{~S}$ с разным содержанием сульфидов цинка и серебра.

\section{2. Эксперимент}

Наиболее перспективным методом синтеза гетеронаноструктур на основе наноструктурированных сульфидов цинка и серебра является осаждение и соосаждение из водных растворов. Водные растворы реагентов для синтеза наноструктурированного сульфида цинка и гетеронаноструктур сульфидов цинка и серебра готовили на высокочистой деионизированной воде. Подробно методика синтеза нанопорошков $\mathrm{ZnS}$ и гетеронаноструктур $\mathrm{ZnS} / \mathrm{Ag}_{2} \mathrm{~S}$ описана в работе [22].

Наноструктурированный сульфид цинка синтезировали химическим осаждением из водных растворов нитрата цинка $\mathrm{Zn}\left(\mathrm{NO}_{3}\right)_{2}$ и сульфида натрия $\mathrm{Na}_{2} \mathrm{~S}$. В качестве комплексообразователя и стабилизатора применяли водные растворы цитрата натрия $\mathrm{Na}_{3} \mathrm{C}_{6} \mathrm{H}_{5} \mathrm{O}_{7} \equiv \mathrm{Na}_{3}$ Cit и Trilon B (EDTA- $\left.\mathrm{H}_{2} \mathrm{Na}_{2}\right)$. Температура синтеза варьировалась от 298 до $323 \mathrm{~K}$, время выдержки наночастиц в реакционной смеси составляло до $100 \mathrm{~h}$.

Для получения гетеронаноструктур $\mathrm{ZnS} / \mathrm{Ag}_{2} \mathrm{~S}$ использовали двухстадийный синтез. Сначала химическим осаждением из водных растворов нитрата серебра $\mathrm{AgNO}_{3}$ и сульфида натрия $\mathrm{Na}_{2} \mathrm{~S}$ в присутствии цитрата натрия синтезировали сульфид серебра. Для получения коллоидных растворов сульфида серебра без примеси $\mathrm{Ag}$ использовали реакционные смеси с небольшим относительным избытком сульфида натрия $\mathrm{Na}_{2} \mathrm{~S}$ и минимальной концентрацией $\mathrm{Na}_{3} \mathrm{Cit}$. Синтез коллоидных растворов $\mathrm{Ag}_{2} \mathrm{~S}$ проводили в темноте в нейтральной среде. Далее к водному раствору нитрата цинка при постоянном перемешивании добавляли Trilon $\mathrm{B}$, затем полученный раствор одновременно смешивали с раствором сульфида натрия и синтезированным коллоидным раствором сульфида серебра. Использование Trilon В способствовало появлению наноструктурированного сульфида цинка на поверхности частиц сульфида серебра и образованию на конечном этапе синтеза гетеронаноструктур $\mathrm{ZnS} / \mathrm{Ag}_{2} \mathrm{~S}$ типа ядро-оболочка.

Составы реакционных смесей, использованных для синтеза нанопорошков $\mathrm{ZnS}$ и гетеронаноструктур $\mathrm{ZnS} / \mathrm{Ag}_{2} \mathrm{~S}$, приведены в таблице. Синтезированные порошки промывали методом декантации. При промывке для уменьшения агломерации наночастиц, разрушения крупных агломератов и равномерного распределения водные растворы в течение $30 \mathrm{~min}$ подвергали воздействию ультразвука в ванне Reltec ultrasonic bath USB1/100-TH. Промытые синтезированные порошки сушили сублимационным методов в лиофильной сушилке Alpha 1-2 LDplus (Martin Christ) при температуре ледового конденсатора $-55^{\circ} \mathrm{C}(218 \mathrm{~K})$. Синтезированные высушенные порошки наноструктурированного сульфида цинка и сульфидных гетеронаноструктур хранили в вакуумном эксикаторе Vacuum Desiccator
Sanplatec MB, вакуумированном до остаточного давления $13.3 \mathrm{~Pa}(0.1 \mathrm{~mm} \mathrm{Hg})$.

Осажденные сульфидные порошки исследовали методом рентгеновской дифракции на дифрактометре Shimadzu XRD-7000 в $\mathrm{Cu} K \alpha_{1,2}$-излучении. Рентгеновские измерения проводили в интервале углов $2 \theta=20-95^{\circ}$ с шагом $\Delta(2 \theta)=0.02^{\circ}$ и временем сканирования $10 \mathrm{sec}$ в каждой точке. Окончательное уточнение структуры синтезированных сульфидных порошков проводили с помощью программного пакета X'Pert Plus [25].

Микроструктуру, размер частиц и элементный химический состав сульфидных порошков изучали методом сканирующей электронной микроскопии (СЭМ) на микроскопе JEOL-JSM LA 6390 с энергодисперсионным рентгеновским анализатором JED 2300 Energy Dispersive X-ray Analyzer и микроскопе FEI Quanta200. Кроме того, средний размер $D$ частиц (более точно - средний размер областей когерентного рассеяния $(\mathrm{OKP}))$ в синтезированных порошках сульфида цинка и гетеронаноструктурах $\mathrm{ZnS} / \mathrm{Ag}_{2} \mathrm{~S}$ определяли рентгенодифракционным методом по уширению дифракционных отражений.

Спектры диффузного отражения регистрировались на спектрофотометре FS-5 с помощью интегрирующей сферы, в качестве эталона отражения использовался оптический фторопласт. Спектры были записаны при комнатной температуре в диапазоне длин волн от 245 до $850 \mathrm{~nm}$ с шагом $0.5 \mathrm{~nm}$ с использованием Хе-лампы непрерывного свечения мощностью $450 \mathrm{~W}$ и фотоэлектронного умножителя с рабочим напряжением $1250 \mathrm{~V}$ в режиме единичного счета фотонов. Дополнительно спектры диффузного отражения гетеронаноструктур $(\mathrm{ZnS})\left(\mathrm{Ag}_{2} \mathrm{~S}\right)_{0.025}$ и $(\mathrm{ZnS})\left(\mathrm{Ag}_{2} \mathrm{~S}\right)_{0.10}$ с малым содержанием сульфида серебра измеряли в диапазоне 220-850 nm при температуре $300 \mathrm{~K}$ на спектрофотометpe Shimadzu UV-2450.

Люминесцентные свойства исследовались в диапазоне 410-820 nm при возбуждении излучением с длиной волны $\lambda=330 \mathrm{~nm}$.

\section{3. Результаты и обсуждение}

Типичные рентгенограммы синтезированных нанопорошков сульфида цинка $\mathrm{ZnS}$ показаны на рис. 1. Нанопорошки $\mathrm{ZnS}$ осаждались из реакционных смесей 1-7 (см. таблицу). Дифракционные отражения всех нанопорошков значительно уширены вследствие малого размера частиц $\mathrm{ZnS}$. Размер $D$ частиц нанопорошков $\mathrm{ZnS}$, определенный по уширению дифракционных отражений, составляет от 2 до $10 \mathrm{~nm}$ (таблица). Проведенный количественный анализ и сравнение с данными [26] показали, что наблюдаемый набор дифракционных отражений соответствует однофазному сульфиду цинка с кубической (пр.гр. $F \overline{4} 3 m)$ структурой типа сфалерита (тип B3). Период кристаллической решетки $a_{\mathrm{ZnS}}$ синтезированных нанопорошков $\mathrm{ZnS}$ составил 0.5344-0.5398 nm. Согласно результатам энергодисперсионного рентгеновского 
Состав реакционных смесей, период решетки $a_{\mathrm{ZnS}}$ и средний размер $D$ частиц сульфида цинка в синтезированных нанопорошках $\mathrm{ZnS}$, средний размер $D$ ядра из $\mathrm{Ag}_{2} \mathrm{~S}$ и толщина $h$ слоя $\mathrm{ZnS}$ в гетеронаноструктурах $\mathrm{ZnS} / \mathrm{Ag}_{2} \mathrm{~S}$

\begin{tabular}{|c|c|c|c|c|c|c|c|c|c|c|c|}
\hline \multirow{3}{*}{ № } & \multirow{3}{*}{ Состав } & \multicolumn{7}{|c|}{ Концентрация реагентов в реакционных смесях, $\mathrm{mmol} \cdot 1^{-1}$} & \multirow{3}{*}{$a_{\mathrm{ZnS}}, \mathrm{nm}$} & \multirow{3}{*}{$D \pm 0.5, \mathrm{~nm}$} & \multirow{3}{*}{$h \pm 1, \mathrm{~nm}$} \\
\hline & & \multicolumn{4}{|c|}{ синтез $\mathrm{ZnS}$} & \multicolumn{3}{|c|}{ синтез $\mathrm{Ag}_{2} \mathrm{~S}$} & & & \\
\hline & & $\mathrm{Zn}\left(\mathrm{NO}_{3}\right)_{2}$ & $\mathrm{Na}_{2} \mathrm{~S}$ & $\mathrm{Na}_{3} \mathrm{Cit}$ & Trilon B & $\mathrm{Ag}\left(\mathrm{NO}_{3}\right)_{2}$ & $\mathrm{Na}_{2} \mathrm{~S}$ & $\mathrm{Na}_{3} \mathrm{Cit}$ & & & \\
\hline 1 & $\mathrm{ZnS}$ & 50 & 50 & - & - & - & - & - & 0.53576 & 2 & - \\
\hline 2 & $\mathrm{ZnS}$ & 50 & 100 & - & - & - & - & - & 0.53995 & 9.5 & - \\
\hline 3 & $\mathrm{ZnS}$ & 50 & 50 & 50 & - & - & - & - & 0.53496 & 4 & - \\
\hline 4 & $\mathrm{ZnS}$ & 50 & 50 & - & 50 & - & - & - & 0.53753 & 5.5 & - \\
\hline 5 & $\mathrm{ZnS}$ & 50 & 50 & - & 25 & - & - & - & 0.53764 & 6 & - \\
\hline 6 & $\mathrm{ZnS}$ & 50 & 50 & - & 12.5 & - & - & - & 0.53754 & 3 & - \\
\hline 7 & $\mathrm{ZnS}$ & 50 & 50 & - & 3.125 & - & - & - & 0.53706 & 2.5 & - \\
\hline 8 & $(\mathrm{ZnS}) \cdot\left(\mathrm{Ag}_{2} \mathrm{~S}\right)_{0.025}$ & 50 & 50 & - & 3.125 & 2.5 & 1.25 & 1 & 0.53755 & $* 10$ & 4 \\
\hline 9 & $(\mathrm{ZnS}) \cdot\left(\mathrm{Ag}_{2} \mathrm{~S}\right)_{0.10}$ & 50 & 50 & - & 25 & 10 & 5 & 1 & 0.53974 & $* 9$ & 4 \\
\hline 10 & $(\mathrm{ZnS}) \cdot\left(\mathrm{Ag}_{2} \mathrm{~S}\right)_{0.25}$ & 50 & 50 & - & - & 25 & 12.5 & 5 & 0.53664 & *28 & 5 \\
\hline 11 & $(\mathrm{ZnS}) \cdot\left(\mathrm{Ag}_{2} \mathrm{~S}\right)_{0.50}$ & 50 & 50 & - & - & 50 & 25 & 10 & 0.53631 & *30 & 5 \\
\hline
\end{tabular}

Примечание. ${ }^{*} D_{\mathrm{Ag}_{2} \mathrm{~S}} \pm 2, \mathrm{~nm}$.

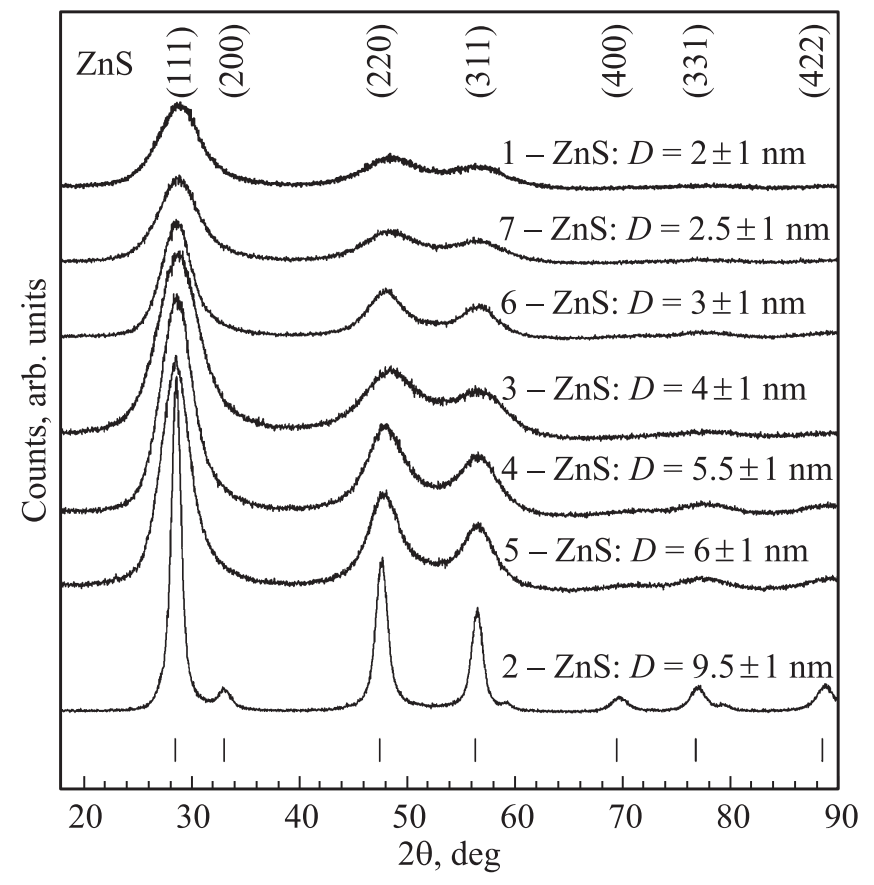

Рис. 1. Рентгенограммы нанопорошков 1-7 сульфида цинка $\mathrm{ZnS} \mathrm{c} \mathrm{разным} \mathrm{размером} \mathrm{частиц.} \mathrm{Нумерация} \mathrm{соответствует}$ таблице.

анализа содержание цинка $\mathrm{Zn}$ и серы $\mathrm{S}$ в синтезированном порошке сульфида цинка со средним размером частиц $\sim 10 \mathrm{~nm}$ составляет $67.1 \pm 0.3$ и $32.7 \pm 0.2 \mathrm{wt} . \%$ (или $50.2 \pm 0.1$ и $49.9 \pm 0.1$ at.\%), что соответствует стехиометрическому сульфиду $\mathrm{ZnS}$.

Рентгенограммы гетеронаноструктур $\mathrm{ZnS} / \mathrm{Ag}_{2} \mathrm{~S}$, осажденных из реакционных смесей 8-11 (таблица), показаны на рис. 2. Количественный анализ рентгенограмм и сравнение с данными [26,27] показали присутствие дифракционных отражений кубического $\mathrm{ZnS}$ и моноклинного $\mathrm{Ag}_{2} \mathrm{~S}$ (рис. 2). В гетеронаноструктурах 8 и 9 интенсивность дифракционных отражений сульфида серебра меньше интенсивности отражений сульфида

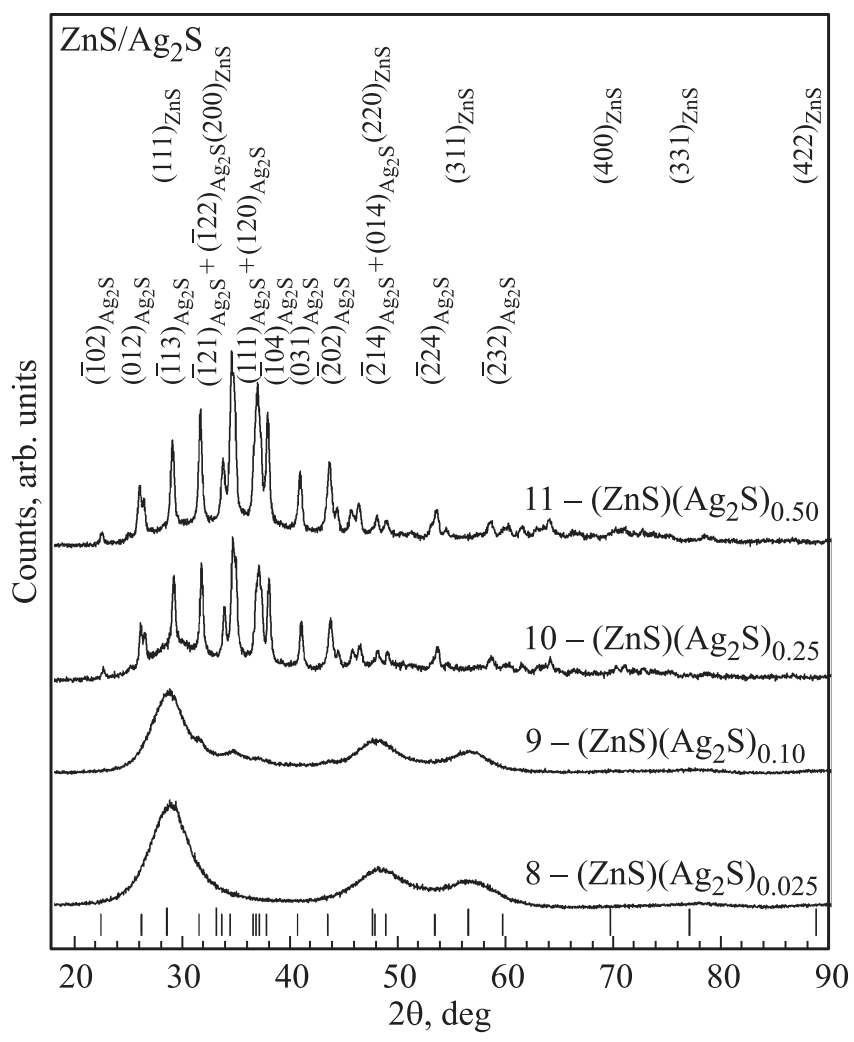

Рис. 2. Рентгенограммы гетеронаноструктур 8, 9, 10 и 11 с разным соотношением $\mathrm{ZnS} / \mathrm{Ag}_{2} \mathrm{~S}$. Нумерация соответствует таблице. Положения дифракционных отражений $\mathrm{ZnS}$ и $\mathrm{Ag}_{2} \mathrm{~S}$ отмечены длинными и короткими вертикальными штрихами соответственно. 


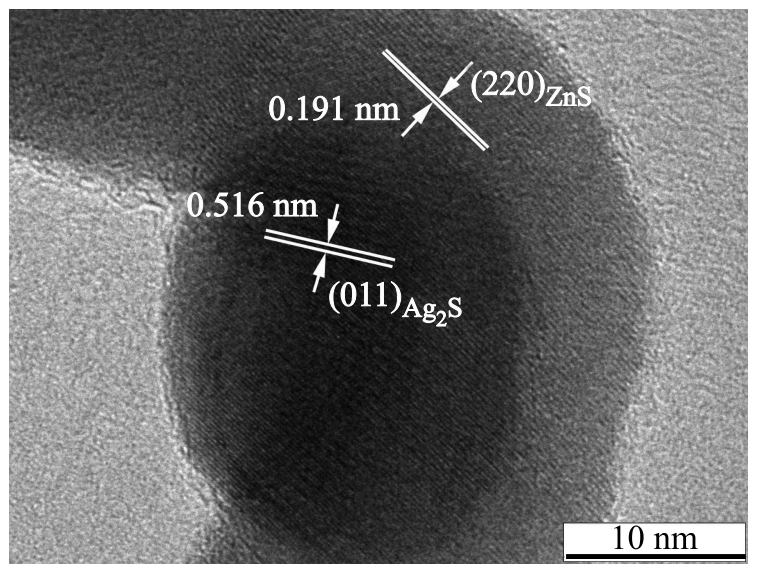

Pис. 3. HRTEM-изображение гетеронаночастицы, полученной из реакционной смеси 9. Ядро наночастицы размером $\sim 10 \mathrm{~nm}$ образовано сульфидом серебра, поверхность наночастицы покрыта слоем кубического сульфида цинка $\mathrm{ZnS}$ толщиной $\sim 4 \mathrm{~nm}$.

цинка вследствие малого относительного содержания $\mathrm{Ag}_{2} \mathrm{~S}$ в них. Дифракционные отражения $\mathrm{Ag}_{2} \mathrm{~S}$ и, особенно, $\mathrm{ZnS}$ в гетеронаноструктурах сильно уширены. Это свидетельствует о малом размере сульфидных частиц, из которых состоят гетеронаноструктуры. Образование гетеронаноструктур подтверждается электронной микроскопией высокого разрешения (HRTEM). Как пример на рис. 3 показано изображение гетеронаночастицы, полученной из реакционной смеси 9 (см. таблицу). Центральная часть наночастицы размером $\sim 10 \mathrm{~nm}$ образована сульфидом серебра, межплоскостное расстояние $0.516 \mathrm{~nm}$ совпадает с расстоянием между атомными плоскостями (011) сульфида серебра с моноклинной (пр.гр. $\left.P 2_{1} / c\right)$ структурой акантита $\alpha-\mathrm{Ag}_{2} \mathrm{~S}$. Поверхность наночастицы покрыта слоем кубического сульфида цинка $\mathrm{ZnS}$ толщиной около $4 \mathrm{~nm}$ : наблюдаемое межплоскостное расстояние $0.191 \mathrm{~nm}$ соответствует расстоянию между атомными плоскостями (220) кубического (пр. гр. $F \overline{4} 3 m$ ) сульфида $\mathrm{ZnS}$. Размер ядра гетеронаночастицы согласуется с размером, оцененным по дифракционным данным (см. таблицу).

На рис. 4 как пример показана рентгенограмма гетеронаноструктуры $(\mathrm{ZnS})\left(\mathrm{Ag}_{2} \mathrm{~S}\right)_{0.25}$, осажденной из реакционной смеси 10 , и ее разложение на составляющие, соответствующие сульфидам $\mathrm{ZnS}$ и $\mathrm{Ag}_{2} \mathrm{~S}$. Количественный анализ показал, что размер частиц $\mathrm{Ag}_{2} \mathrm{~S}$ в этой гетеронаноструктуре составляет примерно $28 \mathrm{~nm}$, а ZnS образует на поверхности частицы сульфида серебра слой толщиной около $5 \mathrm{~nm}$.

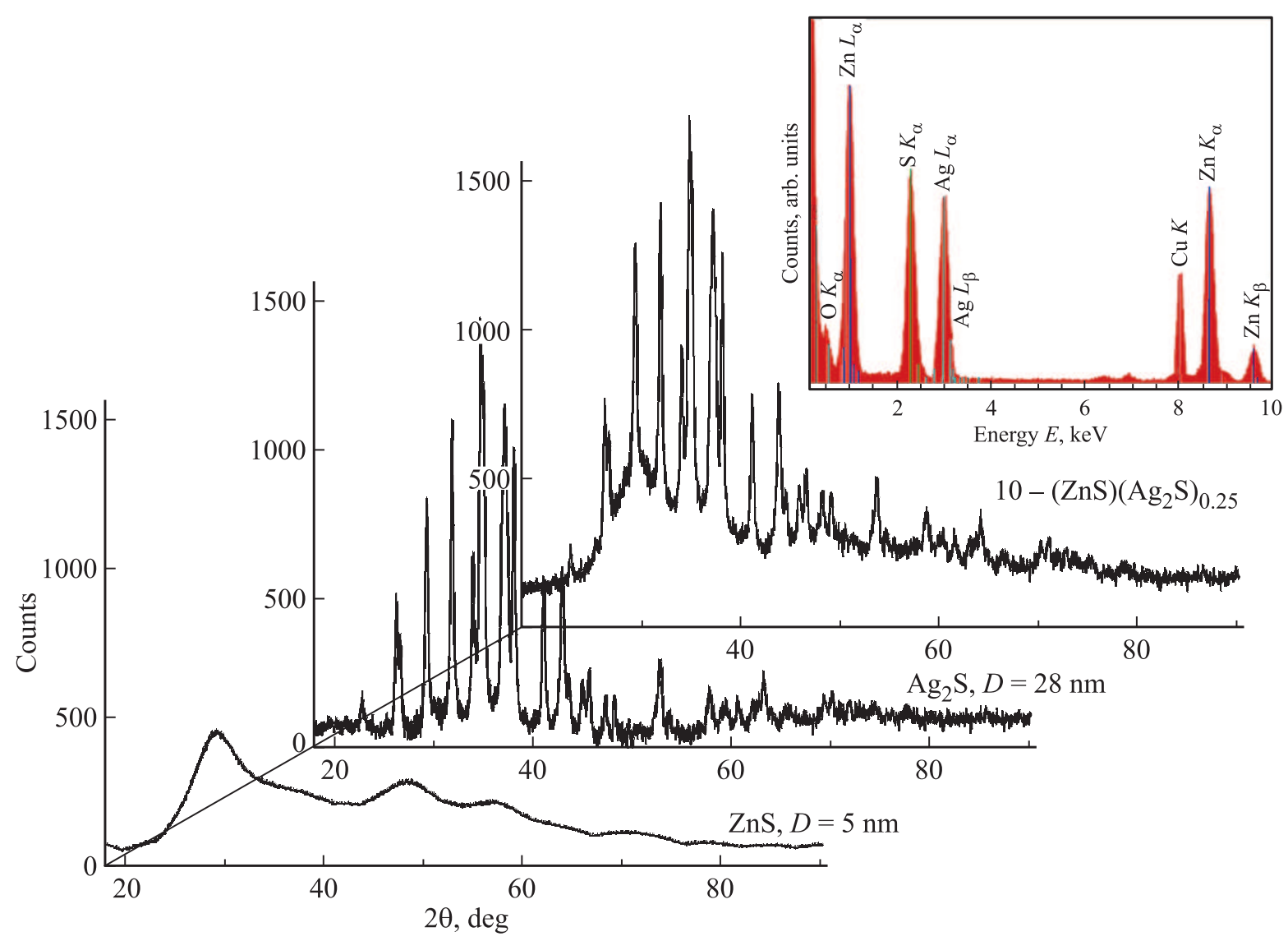

Рис. 4. Разложение рентгенограммы гетеронаноструктуры $10-(\mathrm{ZnS})\left(\mathrm{Ag}_{2} \mathrm{~S}\right)_{0.25}$ на составляющие, соответствующие наноструктурированным сульфидам $\mathrm{ZnS}$ и $\mathrm{Ag}_{2} \mathrm{~S}$. На вставке показан EDX-спектр гетеронаноструктуры $(\mathrm{ZnS})\left(\mathrm{Ag}_{2} \mathrm{~S}\right)_{0.25}$. 
Согласно результатам EDX, содержание цинка Zn, серебра $\mathrm{Ag}$ и серы $\mathrm{S}$ в гетеронаноструктуре 8 составляет $63.1 \pm 0.3,5.2 \pm 0.1$ и $31.7 \pm 0.2$ wt.\% (или $48.2 \pm 0.2$, $2.4 \pm 0.1$ и $49.4 \pm 0.2$ at.\%), а в гетеронаноструктуpe 9 равно $53.4 \pm 0.3, \quad 17.6 \pm 0.2$ и $28.7 \pm 0.2 \mathrm{wt.} \%$ $(43.6 \pm 0.2, \quad 8.7 \pm 0.1 \quad$ и $\quad 47.7 \pm 0.2$ at.\%). По данным энергодисперсионного рентгеновского анализа гетеронаноструктуры 10 (рис. 4, вставка), содержание Zn, $\mathrm{Ag}$ и $\mathrm{S}$ в ней равно $40.9 \pm 0.3, \quad 33.9 \pm 0.2$ и $25.1 \pm 0.2$ wt. $\%(36.2 \pm 0.2,18.1 \pm 0.1$ и $45.3 \pm 0.3$ at.\%). В гетеронаноструктуре 11 содержание $\mathrm{Zn}, \mathrm{Ag}$ и $\mathrm{S}$ составляет $29.6 \pm 0.2, \quad 48.6 \pm 0.3 \quad$ и $21.8 \pm 0.2 \mathrm{wt} . \%$ $(28.6 \pm 0.2,28.5 \pm 0.2$ и $43.0 \pm 0.3$ at.\%) соответственно. C учетом данных EDX и соотношения концентраций реагентов в реакционных смесях 8-11 (см. таблицу), гетеронаноструктуры 8, 9, 10 и 11 имеют примерный состав $(\mathrm{ZnS})\left(\mathrm{Ag}_{2} \mathrm{~S}\right)_{0.025},(\mathrm{ZnS})\left(\mathrm{Ag}_{2} \mathrm{~S}\right)_{0.1},(\mathrm{ZnS})\left(\mathrm{Ag}_{2} \mathrm{~S}\right)_{0.25}$ и $(\mathrm{ZnS})\left(\mathrm{Ag}_{2} \mathrm{~S}\right)_{0.5}$.

Спектры диффузного рассеяния нанопорошков 1-7 сульфида цинка и гетеронаноструктур 10 и 11 (см. таблицу), измеренные в диапазоне длин волн от 245 до $850 \mathrm{~nm}$, показаны на рис. 5. Спектры нанопорошков 1-7 сульфида цинка обладают четко выделенным краем полосы поглощения в области $350-500 \mathrm{~nm}$. В спектрах гетеронаноструктур 8, 10 и 11 край полосы почти не выделен. Ранее аналогичное слабое выделение края полосы наблюдалось в работе [22] в спектрах гетеронаноструктур $(\mathrm{ZnS})\left(\mathrm{Ag}_{2} \mathrm{~S}\right)_{0.025}$ и $(\mathrm{ZnS})\left(\mathrm{Ag}_{2} \mathrm{~S}\right)_{0.10}$.

Для определения оптической ширины запрещенной зоны $E_{g}$ более удобно использовать спектры поглощения. Энергетическая ширина запрещенной зоны описывается функцией

$$
[h v F(R)]^{1 / n}=A\left(h v-E_{g}\right),
$$

где $v=c / \lambda-$ частота падающего излучения, $E=h v$ $=h c / \lambda-$ энергия фотона, $E_{g}-$ ширина щели, $A=$ const - коэффициент, не зависящий от частоты $\omega$, но зависящий от типа перехода. Для оценки коэффициента поглощения $F(R)$ используется функция КубелкиМунка [28] $F(R)=(1-R)^{2} / 2 R$, где $R-$ коэффициент отражения, измеренный в относительных единицах. В случае $\mathrm{ZnS}$ для прямых переходов $n=1 / 2$ и

$$
[h v F(R)]^{2}=A\left(h v-E_{g}\right) .
$$

Уравнение (2) удобно для количественного описания экспериментальных данных по оптическим свойствам и для оценки ширины запрещенной зоны. В реальном эксперименте полоса размыта и поэтому зависимость $[h v F(R)]^{2}=f(h v)$ вблизи края полосы является нелинейной. В этом случае ширина щели $E_{g}$ определяется методом Тауца [29] как длина отрезка, отсекаемого на оси $h v$ касательной к линейной части спектра оптического поглощения, представленного в виде (2).

Рис. 6 показывает спектры поглощения наноструктурированного сульфида цинка $\mathrm{ZnS}$ с размером частиц 2 , $2.5,4$ и $9.5 \mathrm{~nm}$, построенные в энергетической шкале,

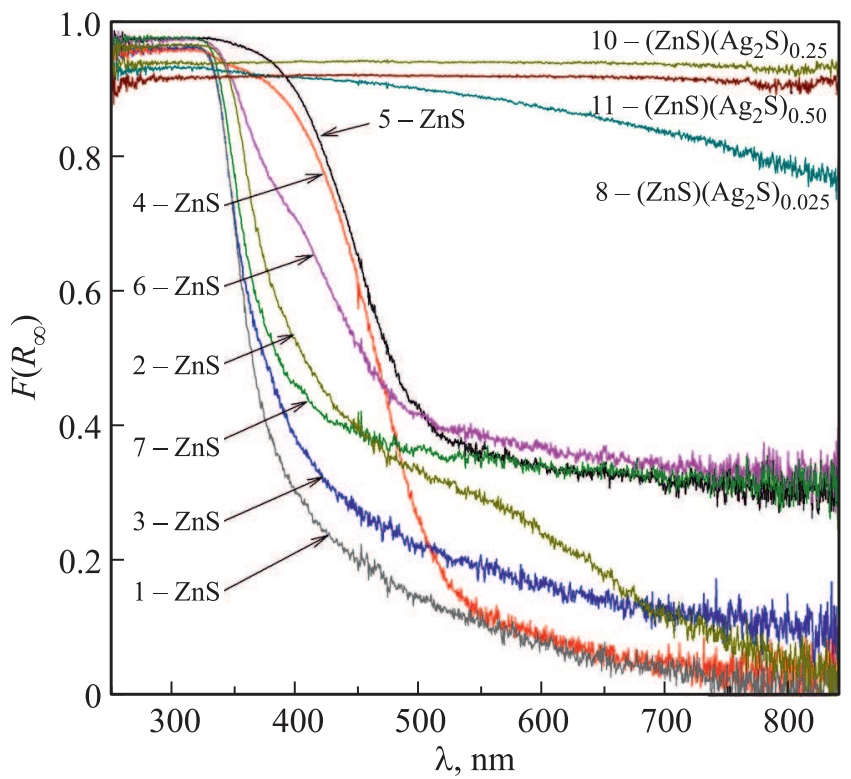

Рис. 5. Спектры диффузного рассеяния нанопорошков 1-7 сульфида цинка $\mathrm{ZnS}$ и гетеронаноструктур 8, 10 и 11. Нумерация соответствует таблице.

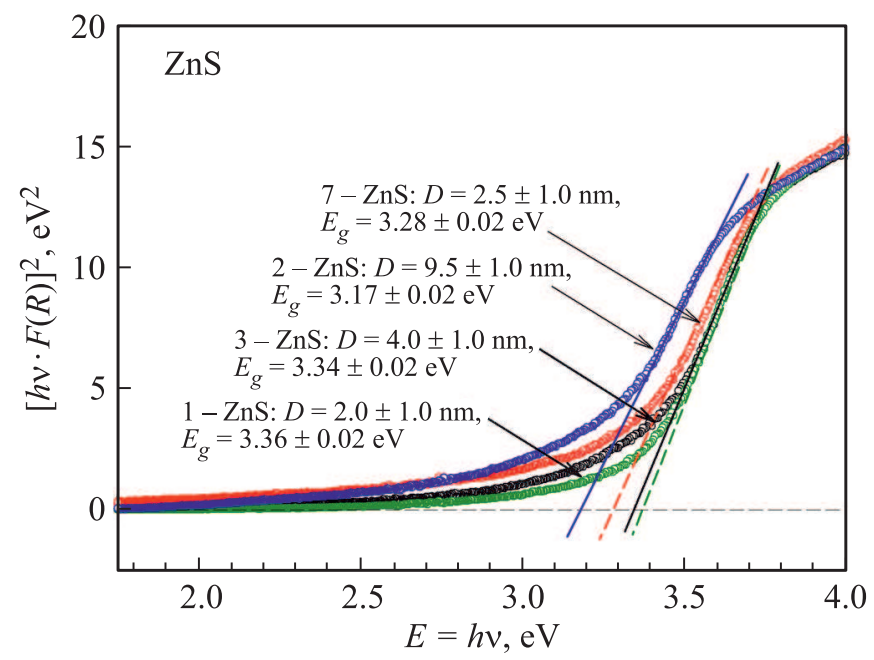

Pис. 6. Спектры оптического поглощения наноструктурированного сульфида цинка $\mathrm{ZnS}: 1-D=2 \pm 1 \mathrm{~nm}$, $E_{g}=3.36 \pm 0.02 \mathrm{eV} ; 2-D=9.5 \pm 1 \mathrm{~nm}, E_{g}=3.17 \pm 0.02 \mathrm{eV}$; $3-D=4 \pm 1 \mathrm{~nm}, E_{g}=3.34 \pm 0.02 \mathrm{eV} ; 7-D=2.5 \pm 1 \mathrm{~nm}$, $E_{g}=3.28 \pm 0.02 \mathrm{eV}$. Нумерация соответствует таблице.

т.е. в координатах $[h v F(R)]^{2}-h v$. Анализ показал, что при уменьшении размера частиц нанопорошков $\mathrm{ZnS}$ от $\sim 10$ до $2 \mathrm{~nm}$ оптическая ширина щели $E_{g}$ увеличивается от $\sim 3.17$ до $\sim 3.36 \mathrm{eV}$. Близость величин $E_{g}$ для наночастиц $\mathrm{ZnS}$ с размером 2.5 и $4.0 \mathrm{~nm}$ обусловлена взаимным наложением ошибок определения $D$ и $E_{g}$, равных $\pm 1 \mathrm{~nm}$ и $\pm 0.02 \mathrm{eV}$ соответственно. Аналогичное увеличение ширины запрещенной зоны с уменьшением размера наночастиц $\mathrm{ZnS}$ наблюдалось в работах $[22,30]$. Возможной причиной пониженной величины $E_{g}$ в нано- 

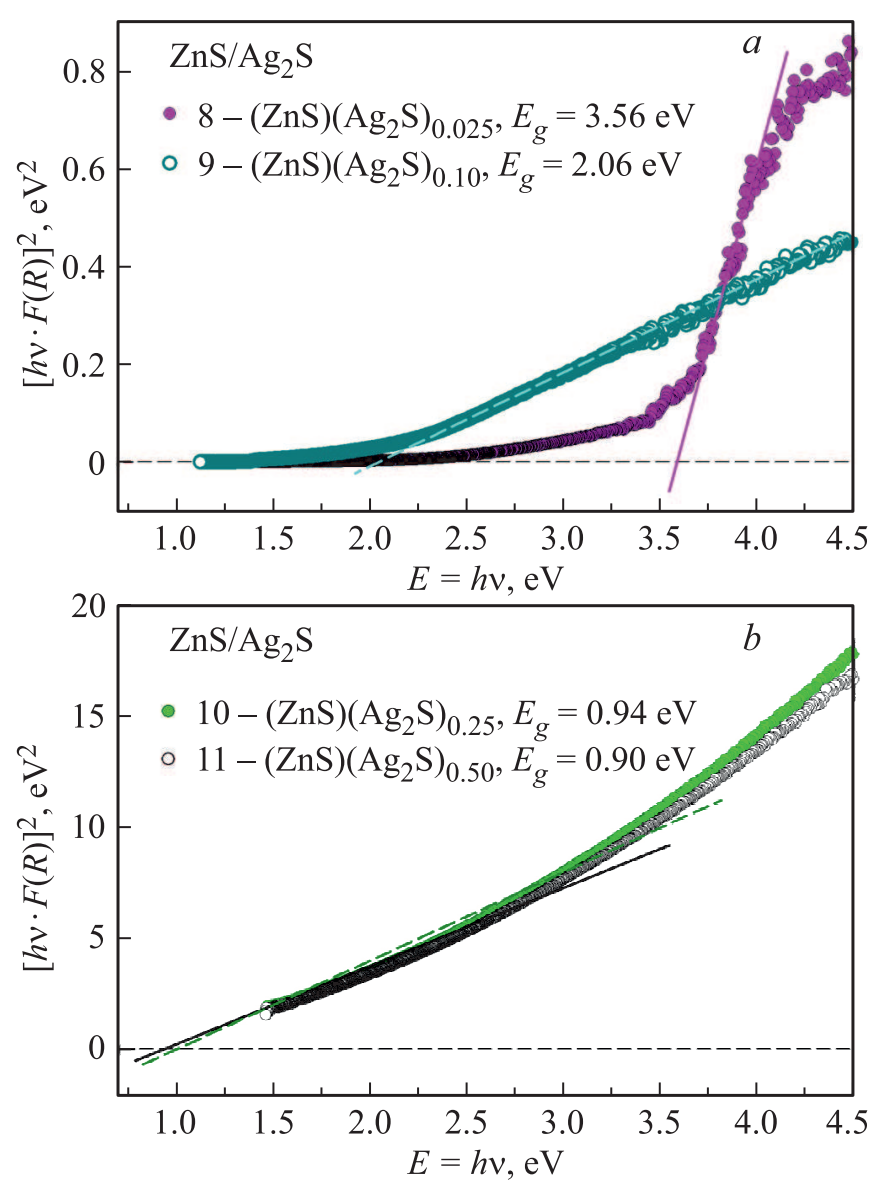

Pис. 7. Спектры оптического поглощения гетеронаноструктур $\mathrm{ZnS} / \mathrm{Ag}_{2} \mathrm{~S}$ : (a) измерения на спектрофотометре Shimadzu UV-2450; $8-(\mathrm{ZnS})\left(\mathrm{Ag}_{2} \mathrm{~S}\right)_{0.025}, \quad E_{g}=3.56 \mathrm{eV}$; $9-(\mathrm{ZnS})\left(\mathrm{Ag}_{2} \mathrm{~S}\right)_{0.10}, E_{g}=2.06 \mathrm{eV} ;(b)$ измерения на спектрофотометре FS-5; $10-(\mathrm{ZnS})\left(\mathrm{Ag}_{2} \mathrm{~S}\right)_{0.25}, E_{g}=0.94 \mathrm{eV} ; 11-$ $(\mathrm{ZnS})\left(\mathrm{Ag}_{2} \mathrm{~S}\right)_{0.50}, E_{g}=0.90 \mathrm{eV}$. Нумерация соответствует таблице.

частицах по сравнению с крупнокристаллическим (bulk) $\mathrm{ZnS}$ могут быть неконтролируемые примеси (возможное слабое окисление поверхностного слоя наночастиц) [9].

Спектры оптического поглощения гетеронаноструктур $(\mathrm{ZnS})\left(\mathrm{Ag}_{2} \mathrm{~S}\right)_{0.025}, \quad(\mathrm{ZnS})\left(\mathrm{Ag}_{2} \mathrm{~S}\right)_{0.10}, \quad(\mathrm{ZnS})\left(\mathrm{Ag}_{2} \mathrm{~S}\right)_{0.25}$ и $(\mathrm{ZnS})\left(\mathrm{Ag}_{2} \mathrm{~S}\right)_{0.50}$, построенные в координатах $[h v F(R)]^{2}-h v$, показаны на рис. 7. К спектрам поглощения исследованных гетеронаноструктур проведены касательные, и величины $E_{g}$ определены по точкам пересечения касательных с осью абсцисс $E=h v$. Край оптического поглощения в спектрах гетеронаноструктур $\mathrm{ZnS} / \mathrm{Ag}_{2} \mathrm{~S}$ (рис. 7) выражен менее четко, чем в случае нанопорошков $\mathrm{ZnS}$. Это обусловлено наличием в гетеронаноструктурах второй фазы - сульфида серебра. Увеличение содержания $\mathrm{Ag}_{2} \mathrm{~S}$ в $(\mathrm{ZnS})\left(\mathrm{Ag}_{2} \mathrm{~S}\right)_{x}$ от $x=0.025$ до $x=0.50$ приводит к размытию края оптического поглощения и уменьшению эффективной оптической ширины щели $E_{g}$ от $3.56 \mathrm{eV}$ в гетеронаноструктуре $(\mathrm{ZnS})\left(\mathrm{Ag}_{2} \mathrm{~S}\right)_{0.025}$ до $0.90 \mathrm{eV}$ в гетеронаноструктуре
$(\mathrm{ZnS})\left(\mathrm{Ag}_{2} \mathrm{~S}\right)_{0.50}$. Это связано с сильным влиянием допирующих добавок на ширину запрещенной зоны наночастиц ZnS. В частности, допирование $\mathrm{ZnS}$ кадмием или серебром (создание гетероструктур $\mathrm{ZnS} / \mathrm{CdS}$, $\mathrm{ZnS} / \mathrm{Ag}_{2} \mathrm{~S}$ ) сопровождается значительным уменьшением величины $E_{g}$ на $0.5-2.6 \mathrm{eV}$ в зависимости от сорта и количества допирующей добавки $[31,32]$. Допирующие ионы работают как центры рекомбинации и сильно влияют на оптические свойства $\mathrm{ZnS}$.

Измерения люминесцентных свойств нанопорошков $\mathrm{ZnS} \mathrm{c} \mathrm{близким} \mathrm{размером} \mathrm{частиц} 2,2.5$ и $4 \mathrm{~nm}$ в диапазоне от 410 до $820 \mathrm{~nm}$ при возбуждении излучением с длиной волны $\lambda=330 \mathrm{~nm}$ (рис. 8) показали, что наноструктурированный сульфид цинка имеет спектр люминесценции с максимумом интенсивности около $430 \mathrm{~nm}$, типичный для крупнокристаллического сульфида цинка [33]. Наблюдаемые спектры связаны с рекомбинацией носителей заряда с участием собственных и примесных дефектов, происходящей по донорно-акцепторному механизму. Та-
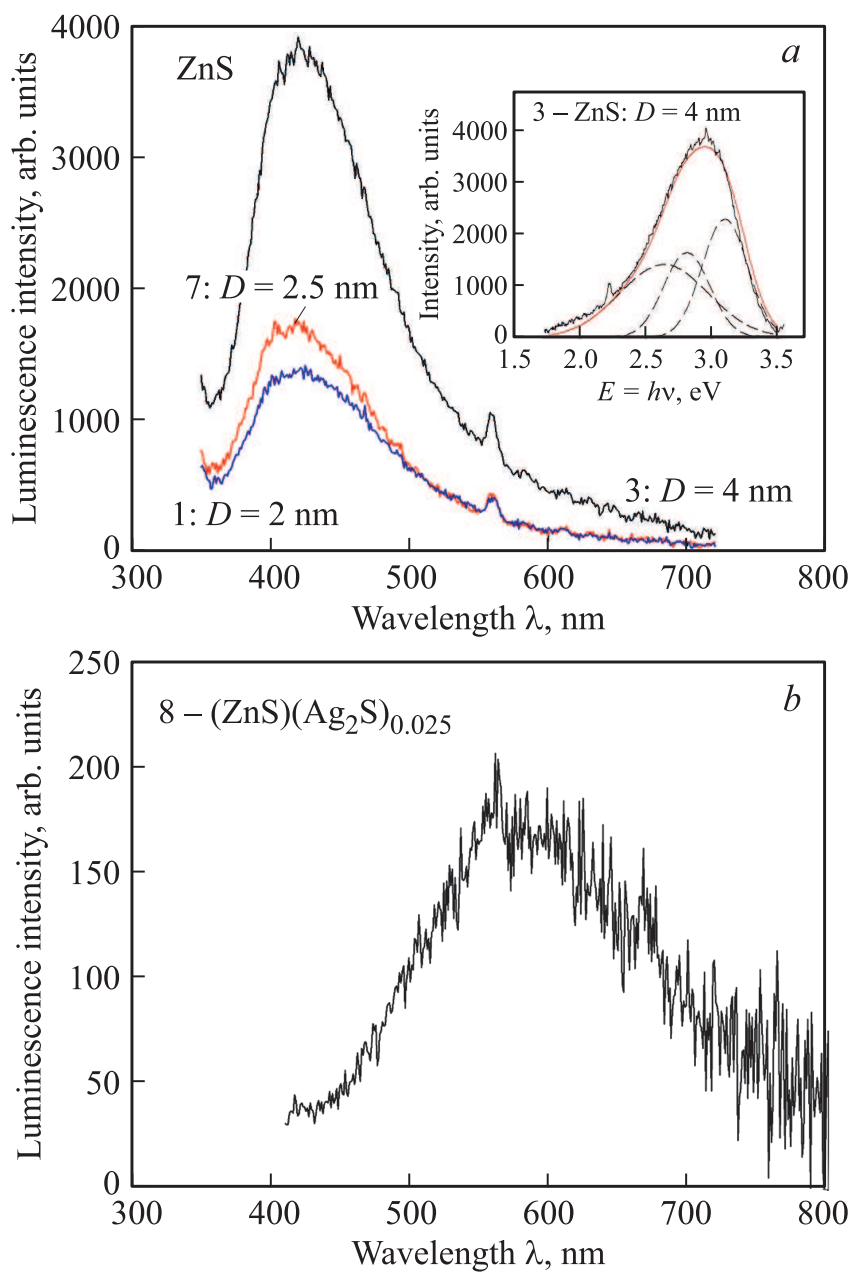

Рис. 8. Спектры люминесценции наноструктурированного сульфида цинка $\mathrm{ZnS} \mathrm{c} \mathrm{разным} \mathrm{размером} \mathrm{частиц}(1-D=2 \mathrm{~nm}$; $3-D=4 \mathrm{~nm} ; 7-D=2.5 \mathrm{~nm})$ и гетеронаноструктуры $8-(\mathrm{ZnS})\left(\mathrm{Ag}_{2} \mathrm{~S}\right)_{0.025}$. На вставке показана аппроксимация спектра люминесценции нанопорошка 3 сульфида цинка тремя гауссианами. Нумерация соответствует таблице. 
ким дефектами могут быть различные неконтролируемые примеси и дефекты в катионной и анионной подрешетках. Заметное отличие в интенсивности люминесценции нанопорошков $\mathrm{ZnS}$ может быть связано с применением разных реагентов при синтезе (см. таблицу). Применение $\mathrm{Na}_{3} \mathrm{Cit}$ при синтезе (образец 3) способствует росту интенсивности люминесценции, тогда применение Trilon В заметно снижает интенсивность свечения (образец 7, синтез из реакционной смеси 7 с концентрацией Трилона Б, равной $3.125 \mathrm{mmol} \cdot 1^{-1}$ ). Нанопорошок $\mathrm{ZnS}$, синтезированный без комплексообразователя (образец 1), имеет наименьшую интенсивность люминесценции.

Спектр люминесценции гетеронаноструктуры $(\mathrm{ZnS})\left(\mathrm{Ag}_{2} \mathrm{~S}\right)_{0.025}$, полученной из реакционной смеси 8 , представляет из себя широкий пик с максимумом около $580 \mathrm{~nm}$. Интенсивность люминесценции гетеронаноструктуры заметно меньше таковой для наноструктурированного сульфида цинка. Существенное уменьшение интенсивности люминесценции гетеронаноструктуры по сравнению с $\mathrm{ZnS}$ обусловлено присутствием $\mathrm{Ag}_{2} \mathrm{~S}$ с узкой энергетической щелью $0.8-1.05 \mathrm{eV}[4,5]$, который имеет сильные полосы поглощения в диапазоне люминесценции $\mathrm{ZnS}$.

\section{4. Заключение}

Нанопорошок сульфида цинка был синтезирован химическим осаждением. Уменьшение размера наночастиц $\mathrm{ZnS}$ от 10 до $2 \mathrm{~nm}$ сопровождалось небольшим увеличением ширины запрещенной зоны $E_{g}$ от 3.17 до $3.36 \mathrm{eV}$.

Гетеронаноструктуры $\mathrm{ZnS} / \mathrm{Ag}_{2} \mathrm{~S}$ были синтезированы двухстадийным гидрохимическим осаждением. Осаждение $\mathrm{ZnS}$ на поверхность наночастиц $\mathrm{Ag}_{2} \mathrm{~S}$ приготовленного коллоидного раствора сульфида серебра привело к образованию гетеронаноструктур $\mathrm{ZnS} / \mathrm{Ag}_{2} \mathrm{~S}$. Добавление к сульфиду цинка сульфида серебра и образование гетеронаноструктур приводит к гораздо большему изменению ширины запрещенной зоны: увеличение содержания $\mathrm{Ag}_{2} \mathrm{~S}$ в гетеронаноструктурах $(\mathrm{ZnS})\left(\mathrm{Ag}_{2} \mathrm{~S}\right)_{x}$ от $x=0.025$ до $x=0.50$ сопровождается уменьшением ширины запрещенной зоны $E_{g}$ от $\sim 3.56$ до $\sim 0.90 \mathrm{eV}$, а также ростом интенсивности полосы поглощения в инфракрасной области.

Наноструктурированный сульфид цинка имеет спектр люминесценции, типичный для крупнокристаллического сульфида цинка. Различие в интенсивности люминесценции нанопорошков $\mathrm{ZnS}$ с близким размером наночастиц связано с применением разных реагентов при синтезе. Существенное уменьшение интенсивности люминесценции гетеронаноструктур $\mathrm{ZnS} / \mathrm{Ag}_{2} \mathrm{~S}$ по сравнению с $\mathrm{ZnS}$ обусловлено присутствием $\mathrm{Ag}_{2} \mathrm{~S}$, который имеет сильные полосы поглощения в диапазоне люминесценции $\mathrm{ZnS}$.

\section{Благодарности}

Авторы благодарят А.В. Ищенко за помощь в измерении двух спектров диффузного отражения гетеронаноструктур с малым содержанием сульфида серебра в Научно-образовательном центре „Наноматериалы и нанотехнологии“ Уральского федерального университета.

\section{Финансирование работы}

Исследование выполнено при финансовой поддержке Российского научного фонда (проект № 19-79-10101) в Институте химии твердого тела Уральского отделения РАН.

\section{Конфликт интересов}

Авторы заявляют, что у них отсутствует конфликт интересов.

\section{Список литературы}

[1] X. Fang, T. Zhai, U.K. Gautam, L. Li, L. Wu, Y. Bando, D. Golberg. Progr. Mater. Sci. 56, 2, 175 (2011).

[2] X. Wang, H. Huang, B. Liang, Z. Liu, D. Chen, G. Shen. Crit. Rev. Solid State Mater. Sci. 38, 1, 57 (2013).

[3] A. Tang, Yu. Wang, H. Ye, C. Zhou, C. Yang, X. Li, H. Peng, F. Zhang, Y. Hou, F. Teng. Nanotechnology 24, 35, 355602 (2013).

[4] C. Cui, X. Li, J. Liu, Y. Hou, Y. Zhao, G. Zhong. Nanoscale Res. Lett. 10, 1, 431 (2015).

[5] S.I. Sadovnikov, A.I. Gusev. J. Mater. Chem. A 5, 34, 17676 (2017).

[6] S.I. Sadovnikov, A.A. Rempel, A.I. Gusev. Nanostructured Lead, Cadmium and Silver Sulfides: Structure, Nonstoichiometry and Properties. Springer Int. Publ. AG, ChamHeidelberg-New York-Dordrecht-London (2018). 331 p.

[7] S.I. Sadovnikov, A.A. Rempel, A.I. Gusev. Russ. Chem. Rev. 87, 4, 303 (2018).

[8] С.И. Садовников, А.И. Гусев, А.А. Ремпель. Полупроводниковые наноструктуры сульфидов свинца, кадмия и серебра. Физматлит, М. (2018). 432 с.

[9] S.I. Sadovnikov. Russ. Chem. Rev. 88, 6, 571 (2019).

[10] T. Kryshtab, V.S. Khomchenko, J.A. Andraca-Adame, A.K. Savin, A. Kryvko, G. Juárez, R. Peña-Sierra. J. Lumin. 129, 12, 1677 (2009).

[11] X. Ma, J. Song, Z. Yu. Thin Solid Films 519, 15, 5043 (2011).

[12] H. Peng, B. Liuyang, Y. Lingjie, L. Jinlin, Y. Fangli, C. Yunfa. Nanoscale Res. Lett. 4, 9, 1047 (2009).

[13] W.P. Lim, Z. Zhang, H.Y. Low, W.S. Chin. Angew. Chem. Int. Ed. 43, 42, 5685 (2004).

[14] A.I. Kryukov, A.L. Stroyuk, N.N. Zin'chuk, A.V. Korzhak, S.Y. Kuchmii. J. Mol. Catal. A 221, 1-2, 209 (2004).

[15] S.I. Sadovnikov, E.A. Kozlova, E.Yu. Gerasimov, A.A. Rempel, A.I. Gusev. Int. J. Hydr. Energy 42, 40, 25258 (2017).

[16] L. Liu, S. Hu, Y.-P. Dou, T. Liu, J. Lin, Y. Wang. Beilst. J. Nanotechnol. 6, 1781 (2015).

[17] [17]C.H. Liang, K. Terabe, T. Hasegawa, M. Aono. Nanotechnology 18, 48, 485202 (2007). 
[18] T.V. Butkhuzi, T.G. Tchelidze, E.G. Chikoidze, N.P. Kekelidze. Phys. Status Solidi B 229, 1, 365 (2002).

[19] H. Zhang, B. Wei, L. Zhu, J. Yu, W.-Sun, L. Xu Appl. Surf. Sci. 270, 133 (2013).

[20] X. Yang, H. Xue, J. Xu, X. Huang, J. Zhang, Y.-B. Tang, T.-W. Ng, H.-L. Kwong, X.-M. Meng, C.-S. Lee. ACS Appl. Mater. Interfaces 6, 12, 9078 (2014).

[21] M. Karimipour, N. Moradi, M. Molaei. J. Lumin. 182, 91 (2017).

[22] S.I. Sadovnikov, A.V. Ishchenko, I.A. Weinstein. J. Alloys Comp. 831, 154846 (2020).

[23] R.G. Chaudhuri, S. Paria. J. Phys. Chem. C 117, 4, 23385 (2013).

[24] G. Murugadoss, R. Jayavel, M. Rajesh Kumar, R. Thangamuthu. Appl. Nanosci. 6, 4, 503 (2016).

[25] X'Pert HighScore Plus. Version 2.2e (2.2.5). ( 2009 PANalytical B.V. Almedo. The Netherlands.

[26] JCPDS card No. 005-0566.

[27] S.I. Sadovnikov, A.I. Gusev, A.A. Rempel. Phys. Chem. Chem. Phys. 17, 19, 12466 (2015).

[28] P. Kubelka, F. Munk. Ztschr. Techn. Physik 11a, 593 (1931).

[29] J. Tauc. Mater. Res. Bull. 3, 1, 37 (1968).

[30] T.T.Q. Hoa, L.V. Vu, T.D. Canh, N.N. Long. J. Phys.: Conf. Ser. 187, 012081 (2009).

[31] X. Fang, T. Zhai, U.K. Gautam, L. Li, L. Wu, Y. Bando, D. Golberg. Progr. Mater. Sci. 56, 175 (2011).

[32] U. Jabeen S.M. Shah, N. Hussain, Fakhr-e-Alam, A. Ali, A. AKhan, S.U. Khan. J. Photochem. Photobiol. A 325, 29 (2016).

[33] M. Saleh, K.G. Lynn, L.G. Jacobsohn, J.S. McCloy. J. Appl. Phys. 125, 7, 075702 (2019).

Редактор Ю.Э. Китаев 